\title{
Urban Infrastructure Development Works in India: Delay and Difficulties in Implementation with Reference to a Water Supply Project
}

\author{
A. K. Aditya $^{1} \cdot$ David Allen Douglass $^{1} \cdot$ Mahua Bhattacharya $^{2}$
}

Received: 17 June 2016/Accepted: 14 July 2017/Published online: 7 September 2017

(C) The Institution of Engineers (India) 2017

\begin{abstract}
A handsome project is undertaken by the Govt. of India with funding under either foreign investments or from their own resources. Though the projects are targeted to be implemented within a certain time frame these are never achieved because of the frequent delay in implementation. This has caused time and cost overruns as well as delay in delivering the benefits to the commuters. An insight into the critical problems and affairs by the experts who are engaged in the process of execution/implementation through various consultants has brought to light some key recurring issues with remedial measures requiring action from the different stakeholders for such projects.
\end{abstract}

Keywords Urban infrastructure development works in India - Delay and difficulties in implementation . Time and cost overrun

\section{Introduction}

Govt. of India (GoI) has taken up a bulk of development works to extend facilities for urban inhabitants. These works include (1) Supply of Potable Water including Water Audits, NRW and leak detection of old existing systems as and where applicable, (2) Sewerage, (3) Storm Water Drainage, (4) Solid Waste Management, (5) Road Transportation including Highways, (6) Tourism,

A. K. Aditya

aap.aad839@gmail.com

1 Project Management Consultant, GWSP, Guwahati, Assam, India

2 Urban Development Department, Govt. of West Bengal, Salt Lake, Kolkata, India
(7) Water Resources and (8) Capacity Building of the Urban Local Body. These projects are executed through foreign funding sources viz. Asian Development Bank (ADB), Japan International Cooperation Agency (JICA), World Bank etc. Some part of such work has also been attempted through JnNURM funding by the GoI from its own investment plan. While some of the project/s is completed some are still ongoing depending on their nature and complexity. Initially these works were taken up in major cities but over the years such projects will spread to the smaller cities as well. Out of 5100 towns and 380 cities (Census 2001) only a few have been covered so far. Supply of potable water is the most important and has priority over all others.

To execute such infrastructure huge investments are required. Implementation of such vast project/s in different city/towns requires involvement of Engineers/Technocrats/ Scientists of various disciplines and Administrators at different levels. Implementation of a project is accomplished by (1) setting up of the Administrative body (owner of the facility) in the ULB or in the State Departments. (2) Selection of Engineer in the shape of Design/Supervision/ Management Consultants etc. Design/Supervision including Management, selection of Contractor, Completion and handing over of project are done by the Consultant engaged.

\section{Reasons of Delays in Implementation}

These delays are analyzed in the ambit of the scope and ground reality. Urban projects are delayed in execution for various reasons which are due to (1) decision making, (2) difficulties in execution and (3) failure of the Contractor to perform. These are discussed in the following Para. 


\section{Delays Due to Administrative Issues}

Following are the few areas which delay the projects described in "Land Acquisition" to "Co-ordination Amongst Different Decision Making Body" sections.

\section{Land Acquisition}

Land is the primary need for any infrastructure. For infrastructure works related to water supply projects a handful of sites are required for construction of different components like Water Treatment Plants, Service Reservoirs and Pumping Stations and Right of Way (ROW) etc. Whatever small may be the quantum of land this is an essential requirement for the project and must be available before procurements starts. The land acquisition process starting from proposal up to getting possession is a very long, tedious and time consuming. So it is to be ensured that land/s are ready in hand before a Contract is signed with the contractor.

The other solution is to allow tendering only for projects where the land has been acquired. May be this is the Lender's (JICA, ADB, WB etc.) intention but for some reason this is waived. If this rule was imposed projects would go much faster (with less cost). There may be a hue and cry at first but soon everyone, including the Contractors, would see the sense in it.

\section{Planning}

Planning is categorized as Engineering Planning including concept planning and Implementation Planning. Most implementation planning ignores land acquisition and permitting, both of which are often significant time components to the projects. Engineers on the job on planning are not provided sufficient time to make out a successful road map for implementation of the project. Before planning is completed work gets started under certain compulsions with the conceptual planning supplied by the concerned department. A well-defined time line required for proper planning which seldom found. The temptation to provide optimistic but unrealistic planning leads to unnecessary time consumption during execution and is to be avoided. Completion of the whole work may differ with actual if a careful look is not given at the planning stage.

\section{Co-ordination Amongst Different Decision Making Body}

Usually many of the departments are involved for such works for which core committees are formed. The decision of the core committee meeting is well percolated to the ground level administration to avoid any confusion and future complications. But getting decisions of such committees is time consuming.

\section{Delays Due to Difficulties in Execution}

During execution of such works in the city roads usually we encounter three problems. (1) It may damage several utility services, disruption of which may cause serious resentments from general public. So it is very important that very safe and systematic procedure to be followed during project execution. (2) Roads are narrow and congested and (3) the whole of the pipe laying works comprises of several sequential works which are to be done one after another. Unless the works at earlier sequences are completed the forward one cannot be taken up. The sequential activities are explained in the light of their inter relation in "Narrow and Congested Roads" to "Road Open to Traffic" sections.

\section{Narrow and Congested Roads}

Disruption of utilities, disruption of roads and pedestrian pathways, are typical in underground work. This is more critical for narrow and congested roads which are prevalent in city area. The presence of road side unauthorized shops and parking of vehicles has narrowed the roads further causing serious hindrances to the pedestrian and traffic movement. Therefore, when pipe laying work is taken up on such roads, inconvenience to general public and traffic system is caused and aggravated further. Sometimes diversion is provided to vehicular movement but regular movement of the pedestrian or close-vicinity residents are not addressed properly. So work becomes slower (Fig. 1).

\section{Existence of Utility Services}

Most of the utility services like water pipe lines, sewers, cable (electrical/telephones etc.) are laid underground. In practice there are several underground existing utility services. Some of them are recent and some are laid long time back and have lost their life and are in a very bad condition. These pipes and cables are easily damaged during routine pipe laying work and supply systems are disrupted. Some of these pipe lines are defunct and not identified due to poor data records from earlier times. Since the water supply, electrical power, and communications are basic needs disruption by any way may cause a serious concern for the administration (Fig. 2). 


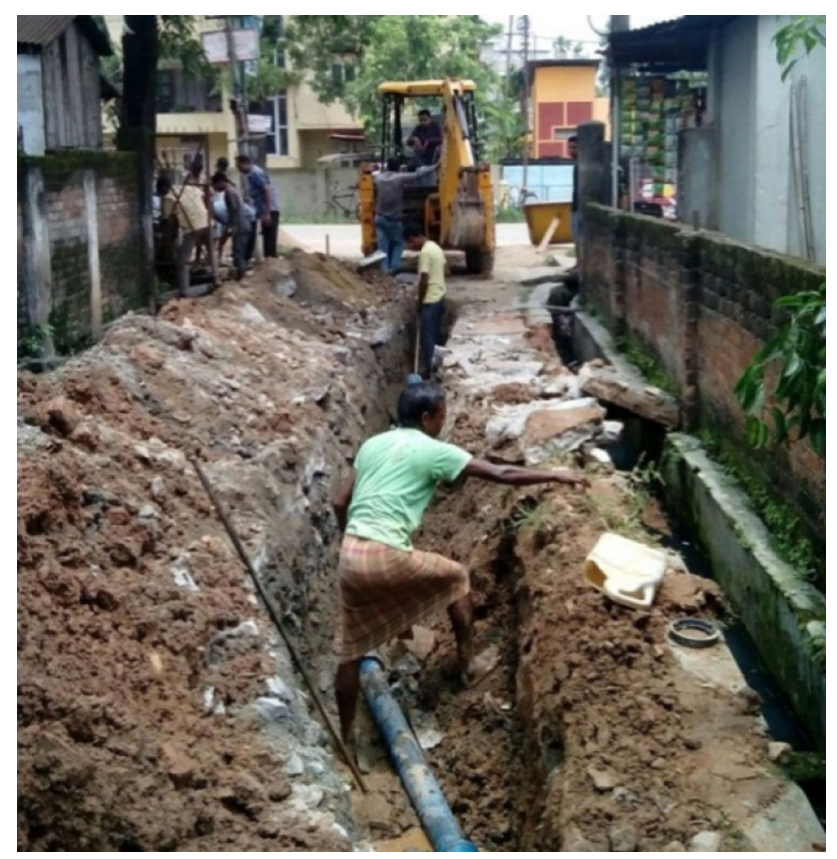

Fig. 1 Narrow and congested road

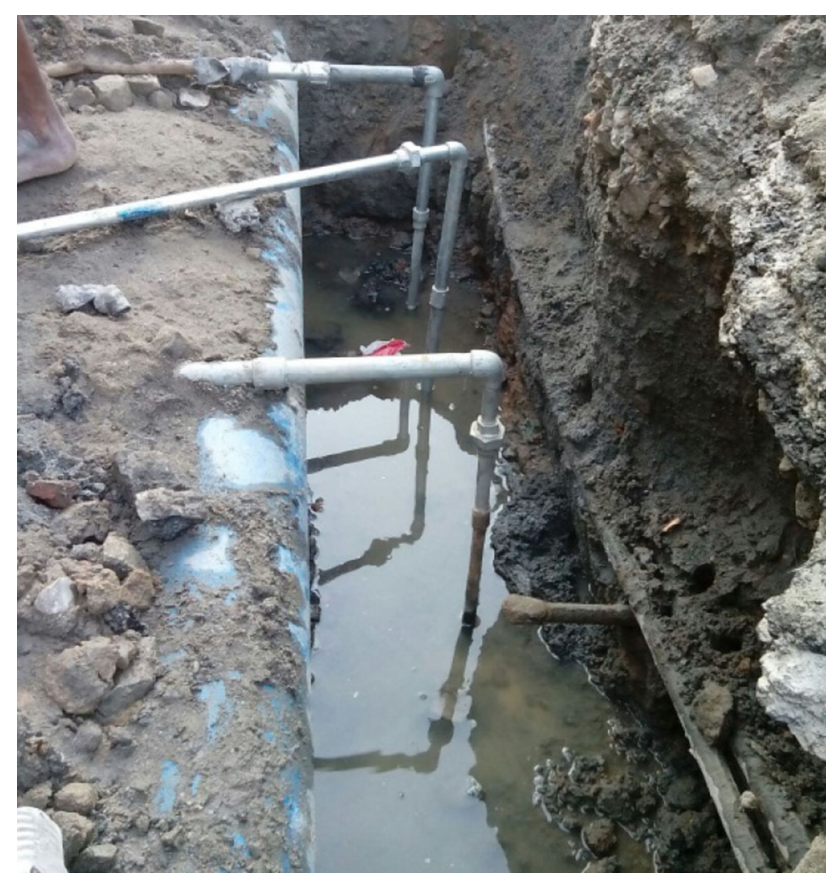

Fig. 2 Existence of utility services

\section{Laying and Jointing of Pipes}

Different dia of pipes are used ranging from 100 to $2000 \mathrm{~mm}$ depending upon the size and nature of the project. The material of construction of pipe also differs. While for smaller dia distribution line DI pipes are used for transmission/lines MS pipes are used for higher dia. Jointing in pipes has varieties. While DI pipes are of

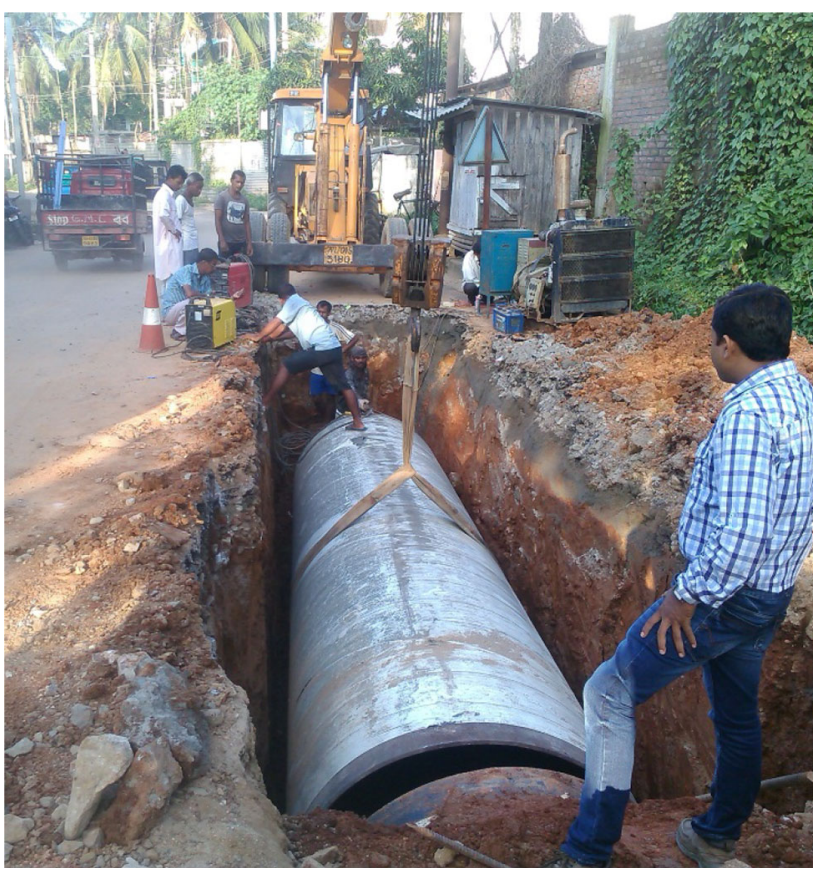

Fig. 3 Laying and jointing of pipes

Socket and Spigot SS joints MS pipes are welded. Both type of joints take time depending upon the accessibility within the available trench width. Time taken for such jointing varies with dia of pipes. Usually DI pipes are $5.5 \mathrm{~m}$ long whereas MS pipes are available in $12 \mathrm{~m}$ or more. Handling of the pipes during lowering within a trench and jointing properly takes time. Lowering of the MS pipes in the trench is a difficult task because of its length and weight. Usually this is done by heavy machinery like Hydra etc. but due to space constraint the minimum maneuvering space is not always available. Moreover, existence of obstructions such as overhead electrical cables etc. makes it more difficult. Extra precaution is required to safeguard the utilities. Welding in the MS pipes is time consuming because of difficulties in arranging of machineries like DG set etc. in the site of work. Testing of the welded joints is again a time consuming matter. Such testing is very restricted in the locality (Fig. 3).

\section{Hydro Testing}

Hydro testing is a compulsory item to ensure there will be no leakage. Hydro testing is done progressively with completion of laying, jointing etc. To perform the test pipe line under test has to be filled with water after plugging both the ends with suitable blank flange or dummy where a pressure-measuring device is placed (Fig. 4).

A Dummy is a device having fitted with the air pipe/vent pipe and gauge fitted on a blank flange which is befitting with the inner dia of the pipe. Care has to be taken to keep 


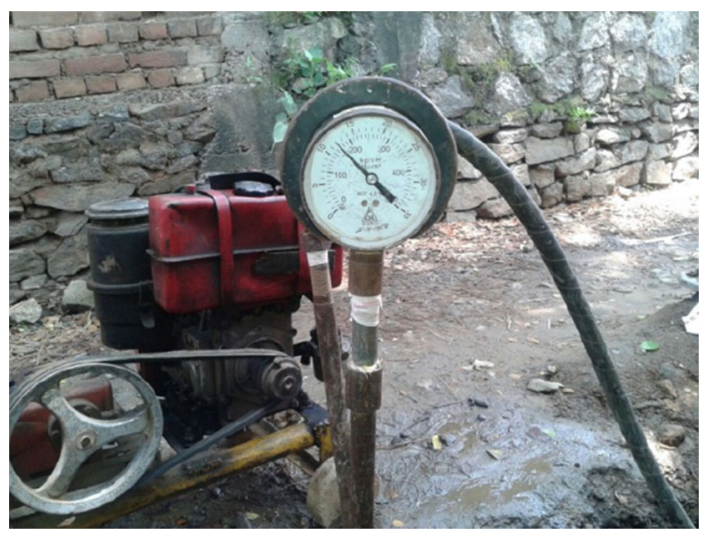

Fig. 4 Hydro testing of pipelines

the blank flange in position with the help of an external counter weight or thrust wall etc. Failures in the Dummy may cause serious accidents causing fatal as well as flooding of the surrounding area. Filling is done by tankers only which is a time taking affair. An external pumping device is to be used to raise the pressure within the pipe to the required degree. These works though looks to be very small but requires utmost care, attention and time. If this test is found positive temporary road restoration is taken up if the valve chamber etc. $r$ is completed in that stretch of the road.

\section{Road Restoration}

Restoration up to Water Bound Macadam (WBM) may allow traffic movement. In the busy city roads prima facie restoration is done with the excavated soil available nearby without proper rolling etc. under the pressure of general public/administration but this strategy often causes more long-term problems for the road authority. In the public interest roads are opened immediately after hydro test and back filling but sufficient care has to be taken to see that the restoration is done maintaining the specs. This rarely happens giving rise to future disputes. It is wise to keep the roads open to traffic after completion of WBM for at least one monsoon for natural consolidation under the care of the contractor so as to have a good base for the final bituminous works etc. (Fig. 5).

\section{Removal of Debris}

The least possible road-width available beside the trench is kept free from debris to allow smooth and free pedestrian movement. When work is undertaken by an experienced contractor it is usually taken care of by engaging either man or machinery but for all practical purposes if the job is sub-contracted to small-capacity contractors who may not comply with any of the above requirements both the

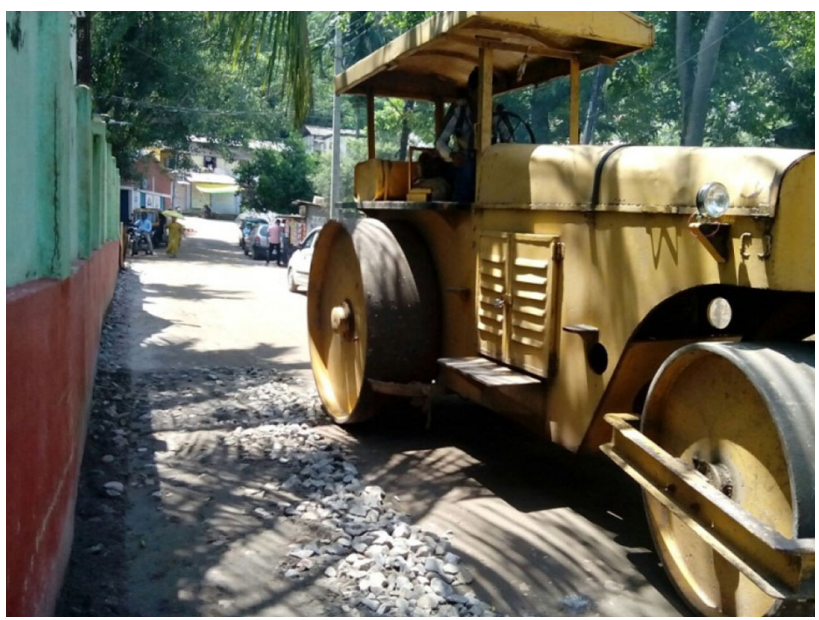

Fig. 5 Stages of road restoration

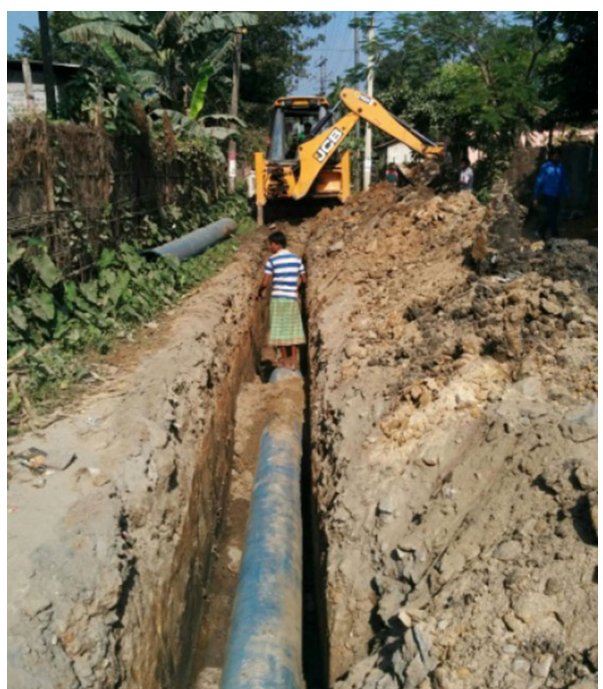

Fig. 6 Removal of debris

Engineers and the Administration will encounter trouble. Movement of heavy machinery is a must for quick and efficient disposal but it is equally dangerous on the city roads where movement of both traffic and public is obvious (Fig. 6).

\section{Road Open to Traffic}

All the above works are time consuming and inter-related and need be done sequentially. But this may cause public resentments. Therefore from digging of the trench up to completing the pipe laying works in all respects consume quite a long time and the road has to be kept under closure. Where some diversion is available the problem is less but for all practical purposes it is not being properly managed at most sites. If the contractor does not have a very good team to handle such sequential activities in a 


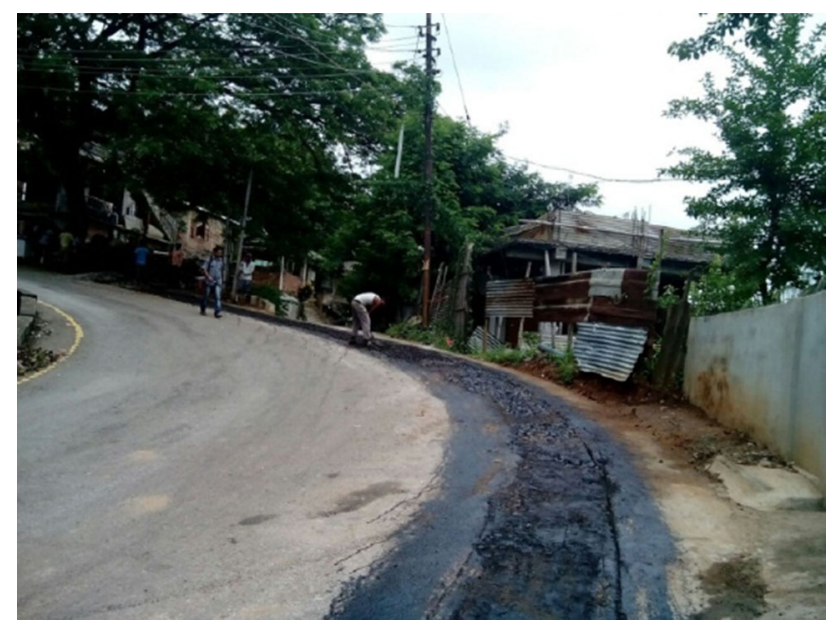

Fig. 7 Road open to traffic

professional manner a realistic time frame given cannot be adhered to. This leads to failure in achieving milestones in the road map. The contract must bind payment terms in such away that it pushes the Contractor to complete pipeline segments, including hydro-testing and road restoration in one go to enable receiving payment (Fig. 7).

Apart from above delay is also due to non-performance of the contractor which is taken up in next Para.

\section{Non-performance of the Contractors}

Contractors are the key players in any project. They very often fail to meet the obligations of the contract during execution but safeguard their own interests and divert the responsibility on the Departments/Engineer. Of course there are good contractors too who are lawful and abide by the contractual obligations. In most of the cases it is seen that a considerable delay is due to non-performance of the contractor. These are described as follows.

\section{Inadequate Resource Mobilization}

In many cases contractor do not deploy the required resources for timely completion of the job. Though timely completion may bring more money for them it is often not done because of the improper and inefficient management by the contractor. The deployment schedule they submit is rarely matching with the requirement of the work and result is delay.

\section{The Improper Use of the Advance Payment}

Mobilization advance should be paid only when materials, equipment, and personnel are physically on the ground at the site. This should be implemented in some fashion.
Typically the Contractors divert the mobilization advance to other uses and thus create a $10 \%$ debt for themselves before starting the work. This creates a disaster to the Contractor's cash flow.

\section{Lack of Professionalism and Cash Flow}

The contractor fails to adopt the set procedures required to achieve the target due to their negligence and sometimes due to their reluctance. It is seen that the contractor is often suffering from the cash flow. This is sometime caused due to delays in processing of the bills of the contractor. But in most of the cases it happens due to inaccurate investment plan that is required to execute the work resulting in delay of the project.

\section{Road Closure Permission}

In some cases road closure permission is obtained in part but not in full. It does not permit the contractor to deploy their full-fledged resources to do the job in a minimum time span in economical way. This needs intervention from the Administration to avoid delays.

\section{Interruption of Works During Long and Short Term Festivals}

The working man days become lesser and lesser than estimated due to the presence of long and short term festivals causing serious setback to the projects. The locations of the festival and their duration are of great concern. This needs a proper planning by the contractor to execute the work within the available frame work. It is an administrative problem and is difficult to sort it out but requires attention. The work is carried out with Migrant labors and when they leave no alternative gang is available when work suffers.

\section{Conclusion}

Attention is to be drawn to following points-(1) Land acquisition must be done beforehand so that the contractor can be given possession of a land free from any encumbrances immediately after mobilization. (2) The Engineering Planning must be accurate as far as to $80 \%$ of perfection. The implementation Plan has to be at least $80-90 \%$ accurate and to the line and direction of the target (prepared by Engineer). Any pending land or ROW acquisition must be accounted for in the implementation plan (Gantt chart). (3) Administration has to cooperate conveying decisions, road closure permission etc. quickly to the Contractor and Engineer to avoid delay. (4) Time is 
the essence of the contract. So Contractors must have the faith and obligation to the contract. Contractors shall not try to skip the obligation of the contract but adhere to it which they are found to comply seldom. Contractors must accept the penalty/delay damages for delays attributable to the contractor. (5) Engineers must be very firm and specific in handling the disobedience of the contractors as per terms of the contract by issuing notices, imposition of penalty, delay damage and termination etc. with appropriate safeguard to legal implication so that it may not bring the project to a halt. (6) Employer to take a positive look to the recommendations of the Engineers in implementation. 